\section{ORIGINAL ARTICLE}

AFRICAN JOURNAL OF CLINICAL AND EXPERIMENTAL MICROBIOLOGY AJCEM/201099/21125

COPYRIGHT 2011

AFR. J. CLN. EXPER. MICROBIOL 12(3): 124-127
SEPTEMBER $2011 \quad$ ISBN 1595-689X VOL 12(3)

-http://www.ajol.info/journals/ajcem doi: $10.4314 /$ ajcem.v12i3.7

\title{
IN-VITRO EFFICACY OF ANTIMICROBIAL AGENTS USED IN THE TREATMENT OF BACTERIAL EYE INFECTIONS IN IBADAN, NIGERIA
}

\author{
${ }^{1}$ D. Olusoga Ogbolu, ${ }^{1}$ O. A. Terry Alli, ${ }^{1}$ Ephraim I. E, ${ }^{2}$ F. A. Olabiyi, ${ }^{3}$ O. A. Daini \\ ${ }^{1}$ Department of Biomedical Sciences, College of Health Sciences, (Osogbo Campus), Ladoke Akintola University of Technology, \\ Ogbomoso. \\ ${ }^{2}$ Department of Chemical Pathology, University College Hospital, Ibadan \\ ${ }^{3}$ Department of Biochemistry, College of Health Sciences, Olabisi Onabanjo University, Ago-Iwoye, Remo Campus, Ikenne, Nigeria.
}

\section{Running Title: In-vitro efficacy of antimicrobial agents in Ibadan, Nigeria}

Correspondence: Ogbolu D. Olusoga (olusogadave@yahoo.com)

\begin{abstract}
Failure to cure eye infections, and reduced potency in topical antimicrobials had been observed in South Western Nigeria, this study sought to evaluate in vitro, the efficacy of antimicrobial agents in the treatment of ocular infections. A total of 46 ocular bacterial isolates were recovered from the diagnostic laboratory of the University College Hospital, Ibadan, from conjunctival swabs of patients having underlying eye diseases (Cataracts, glaucoma and esotrapia), and from patients presenting with other symptoms of eye infections. The pathogens incriminated were Staphylococcus aureus (73.5\%), Coagulase negative Staphylococci (13.3\%), Klebsiella species (10.3\%), and Pseudomonas aeruginosa (2.0\%). Disc diffusion tests (Bauer-Kirby method) were carried out using ciprofloxacin, gentamicin, chloramphenicol, erythromycin, augmentin, cefuroxime and levofloxacin. Broth dilution techniques were thereafter performed using gentamicin, chloramphenicol and ciprofloxacin. The microlide- erythromycin was $63.0 \%$ efficacious, augmentin and cefuroxime showed 71.1\% and $76 \%$ efficacy. Minimum inhibitory concentrations (MIC) of commonly used topical antibiotics however showed different levels of resistance. Resistance to the aminoglycosides was marked, yielding 53.4\% with MIC50=8, MIC90 > 256, Resistance to chloramphenicol was even more marked $69.6 \%$ with $\mathrm{MIC50}=16, \mathrm{MIC} 90=64$, the fluoroquinolones showed high efficacy- levofloxacin and ciprofloxacin showed $93.4 \%$ and $82.6 \%$ susceptibility respectively with MIC50 < 0.5 , though slightly demonstrable resistance was observed (MIC90=8). The study thus recommends the discontinuation of empirical therapy by physicians in order to stem the tide of resistance; it justifies the inclusion of the fluoroquinolones in susceptibility testing of ocular bacterial isolates, and its first line of choice if cure is warranted.
\end{abstract}

\section{Introduction}

Ocular bacterial flora includes Corynebacterium xeroisis, Moraxella catarrhalis, and Staphylococcus epidermidis (1). The coagulase negative staphylococci, a subject of debate in the 1980s, regarding its role in pathogenicity, are remarkable for its opportunism. It has thus been incriminated in chronic blepharitis (2), corneal ulcers, and endophthalmitis after traumatic eye surgery (3). Globally, $S$. aureus is the leading cause of conjunctivitis (3). The incidence of methicillin resistant Staphylococcus aureus (MRSA) in ocular infections is on the rising side (4). In Onitsha, Nigeria, $S$. aureus is the leading cause of conjunctivitis and keratitis (5). Pseudomonas aeruginosa is also leading causes of corneal ulcers especially among contact lens wearers (6). Neisseria gonorrheae and Chlamydia trachomatis cause severe conjunctivitis in the newborn - ophthalmia neonatorum (7). Haemophilus species, Streptococcus pneumoniae (8) and non fermenting coliforms have been implicated in ocular infections (6).

The aminoglycosides gentamicin and tobramycin are well established as first-line therapy for external ocular infections, and possess a broad spectrum of activity against Gram positive and Gram negative organisms $(9,10)$. However, resistance to these antibiotics has been reported. For example, resistance to topical aminoglycoside therapy may be encountered in as many as $8 \%$ to $10 \%$ of ulcerative keratitis cases caused by Pseudomonas aeruginosa (11). Resistance appears to be even greater in ocular infections caused by Gram positive organisms (12). The in-vitro studies of antibacterial susceptibility tests by various authors have shown increasing resistance of commonly used antibacterials; gentamicin (21\%) (4,13), chloramphenicol, though potent against MRSA strains, has just been demonstrated to show significant reduction in its bacteriostatic action in Europe (14.1\%), (14). However, ciprofloxacin, which is still comparatively the most efficacious, has also shown reduced potency; resistance at $35 \%$ was shown in Pittsburg, USA (15), ciprofloxacin has also shown reduced potency against ocular MRSA isolates in the United States (16).

These differing levels of resistance impel an evaluation of these drugs in Nigeria in order to ascertain their efficacy and have a documented level of susceptibility to these agents. The study was therefore aimed at evaluating invitro susceptibility patterns of ocular clinical isolates to commonly used antibiotics, with emphasis on gentamicin, chloramphenicol and ciprofloxacin due to the availability of their topical applications (eye drops). 


\section{Materials and Methods}

Bacterial strains

A total of 46 bacterial isolates were isolated by standard procedures (17) from 136 eye swabs and scrapings sent to the diagnostic laboratory of Medical Microbiology and Parasitology department, University College Hospital, Ibadan from January to October 2009.

\section{Disc susceptibility testing}

Varying concentrations of antibiotics discs; gentamicin (10 $\mu \mathrm{g})$, ciprofloxacin $(10 \mu \mathrm{g})$, methicillin $(5 \mu \mathrm{g})$, chloramphenicol $(10 \mu \mathrm{g})$, erythromycin $(5 \mu \mathrm{g})$, ampicillin $(10 \mu \mathrm{g})$, cloxacillin $(5 \mu \mathrm{g})$, cefuroxime $(30 \mu \mathrm{g})$, augmentin $(10 \mu \mathrm{g})$, and levofloxacin $(10 \mu \mathrm{g})$ were used. Inhibition zone diameters around the discs were measured to the nearest millimetre using a calibrated transparent ruler. The susceptible inhibition zone diameter break point used throughout the study for each antibiotic to the various organisms was based on CLSI recommendation (18). The diameters of the zone of inhibition were recorded. Growth within the zone of inhibition was recorded as resistant (18). Sensitivity patterns for Staphylococcus, Pseudomonas and Klebsiella were compared with the standard $S$. aureus ATCC 29213; P. aeruginosa NCTC 10662 and E. coli NCTC 10418, respectively.

\section{Minimum inhibitory concentration}

The minimum inhibitory concentration (MIC) of 3 antibiotics; gentamicin, chloramphenicol and ciprofloxacin for all the bacterial strains was determined as described by Goldstein and Acar (19). The antibiotics were supplied in powdery formulations, namely; gentamicin, chloramphenicol and ciprofloxacin by SIGMA-ALDRICH, U.K. Serial doubling dilutions of these antibiotics were made, ranging from 0.0625 to $512 \mu \mathrm{g} / \mathrm{ml}$. A drop $(0.02 \mathrm{ml})$ of standard inoculum (0.5 Macfarland) of organisms was introduced and these were then incubated at $37^{\circ} \mathrm{C}$ for 18 hours. MIC was interpreted as the least concentration or highest dilution with no observable turbidity. Controls were set up namely; sterility control: Mueller Hinton broth only, viability control: Mueller Hinton broth and test organism, positive control: Mueller Hinton broth with antibiotics and the control organisms. They were incubated at $37^{\circ} \mathrm{C}$ overnight.

\section{Result}

Bacteria isolates recovered were Staphylococcus aureus 34 (73.9\%), coagulase negative staphylococci (CNS) 6 (13\%), Klebsiella species 5 (10.8\%) and Pseudomonas aeruginosa $1(2.2 \%)$. The distribution of the various isolates with underlying eye conditions, and ocular infections are shown in Figure 1.
Figure 1: Percentage (\%) distribution of conjunctival bacterial isolates.

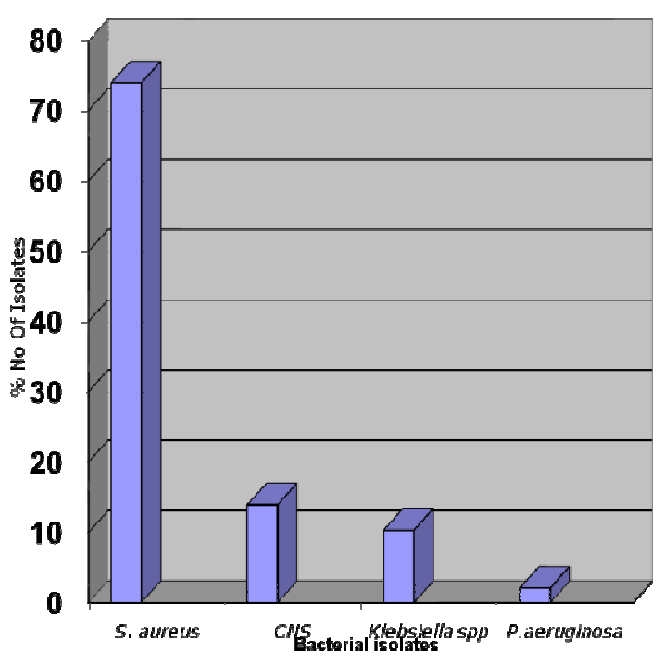

All the strains examined showed resistance to one or more of the eight antibiotics used for this study. The results depicted a high level resistance. The fluoroquinolones showed slightly lower level of resistance than the rest of the antibiotics including the third generation cephalosporins. More isolates were sensitive to levofloxacin (93.4\%) and ciprofloxacin $(76 \%)$ than all the antibiotics tested (Table 1). Similarly, susceptibility of the strains to methicillin was $10.4 \%$; $30.4 \%$ for chloramphenicol while gentamicin had $41.3 \%$ (Figure 2). It is noteworthy that chloramphenicol had no activity against Klebsiella species and Pseudomonas aeruginosa in this study.

Figure 2: Percentage susceptibility to chloramphenicol, gentamicin and ciprofloxacin (disk diffusion test).

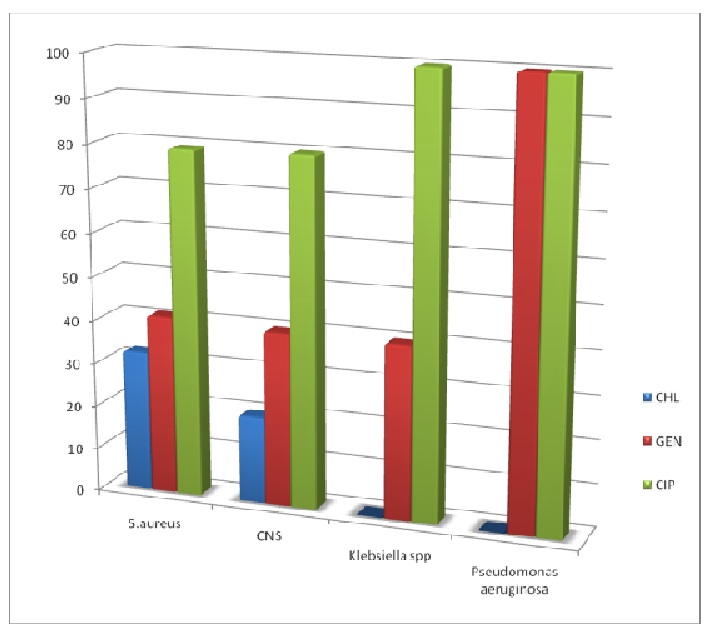


The MIC results also showed that the level of resistance to many antibiotics was high. MIC50 and MIC90 of ciprofloxacin were lower than the rest of the antibiotics. MIC $_{90}$ of gentamicin to the strains was very high with value $>256 \mu \mathrm{g} / \mathrm{ml}$ (Table 2).

\section{Discussion}

The study showed $S$. aureus as the most frequently incriminated conjunctival pathogen, this is consistent with previous studies in Nigeria (20), and outside the country (21). Methicillin-resistant $S$. aureus (MRSA) and Methicillin resistant coagulase negative staphylococci (MRCNS) are intraocular pathogens. They all however have a common source; the anterior nares (22), which via the nasolacrimal duct, may reach the conjunctiva or infect deeper ocular structures; endophthalmitis may ensue (23). The isolation of MRSA from patients having cataracts and glaucoma $(92.3 \%)$ is therefore alarming. The definitions of these conditions do not presuppose a microbial cause. Their incrimination may thus imply the likelihood of subsequent infections that further destroy ocular tissues, and increased susceptibility of these patients to ocular infections. Ultimately, if it be ascertained that these pathogens are simply microflora, it should be alarming from a general epidemiological perspective of resistance, as well as the serious dangers posed these patients if a surgery would be carried out to correct these conditions.

Table 1: Susceptibility patterns of bacterial pathogens using disc diffusion

\begin{tabular}{|c|c|c|c|c|c|c|c|c|c|c|c|c|c|c|c|c|c|c|c|c|c|c|c|c|}
\hline \multirow[t]{2}{*}{ Organism } & \multicolumn{3}{|c|}{ MET } & \multicolumn{3}{|c|}{ CHL } & \multicolumn{3}{|c|}{ GEN } & \multicolumn{3}{|c|}{ CIP } & \multicolumn{3}{|c|}{ ERY } & \multicolumn{3}{|c|}{ AUG } & \multicolumn{3}{|c|}{ LEV } & \multicolumn{3}{|c|}{ CXM } \\
\hline & $\mathbf{S}$ & I & $\mathbf{R}$ & $\mathbf{S}$ & I & $\mathbf{R}$ & $\mathbf{S}$ & I & $\mathbf{R}$ & $\mathbf{S}$ & I & $\mathbf{R}$ & $\mathbf{S}$ & I & $\mathbf{R}$ & $\mathbf{S}$ & I & $\mathbf{R}$ & $\mathbf{S}$ & I & $\mathbf{R}$ & $\mathbf{S}$ & I & $\mathbf{R}$ \\
\hline S. aureus (34) & 3 & $\mathbf{0}$ & 31 & 11 & 0 & 23 & 14 & 2 & 18 & 26 & 2 & 6 & 24 & 0 & 10 & 27 & $\mathbf{0}$ & 7 & 31 & $\mathbf{0}$ & 3 & 30 & $\mathbf{0}$ & 4 \\
\hline CNS (5) & 2 & $\mathbf{0}$ & 3 & 1 & $\mathbf{0}$ & 4 & 2 & $\mathbf{0}$ & 3 & 4 & $\mathbf{0}$ & 1 & 3 & $\mathbf{0}$ & 2 & 3 & $\mathbf{0}$ & 2 & 5 & 0 & 0 & 3 & $\mathbf{0}$ & 2 \\
\hline Klebsiella spp (5) & $\mathbf{0}$ & $\mathbf{0}$ & 5 & $\mathbf{0}$ & $\mathbf{0}$ & 5 & 2 & $\mathbf{0}$ & 3 & 4 & $\mathbf{0}$ & 1 & 2 & $\mathbf{0}$ & 3 & 2 & $\mathbf{0}$ & 3 & 5 & $\mathbf{0}$ & 0 & 2 & $\mathbf{0}$ & 3 \\
\hline P. aeruginosa (1) & $\mathbf{0}$ & $\mathbf{0}$ & 1 & $\mathbf{0}$ & $\mathbf{0}$ & 1 & 1 & 0 & 0 & 1 & 0 & 0 & 0 & 0 & 1 & 1 & $\mathbf{0}$ & 0 & 1 & 0 & 0 & 0 & 0 & 1 \\
\hline
\end{tabular}

MET- methicillin, CHL- chloramphenicol, GEN- gentamicin, CIP- ciprofloxacin, ERY-erythromycin, AUG- augmentin, LEV- levofloxacin, CXM- cefuroxime, S- susceptible, I- intermediate, R- resistant.

Table 2: Minimum inhibitory concentrations of common antimicrobials to the pathogens

\begin{tabular}{|c|c|c|c|c|}
\hline Organism & $\begin{array}{c}\text { Antimicrobial } \\
\text { Agent }\end{array}$ & $\mathrm{MIC}_{50}(\mu \mathrm{g} / \mathrm{ml})$ & $\mathrm{MIC}_{90}(\mu \mathrm{g} / \mathrm{ml})$ & Range $(\mu \mathrm{g} / \mathrm{ml})$ \\
\hline \multirow[t]{3}{*}{ MRSA (30) } & Chloramphenicol & 24 & 64 & $0.25-256$ \\
\hline & Gentamicin & 8 & $>256$ & $0.25-256$ \\
\hline & Ciprofloxacin & 0.25 & 8 & $0.25-256$ \\
\hline \multirow[t]{3}{*}{ MSSA (3) } & Chloramphenicol & 16 & 32 & $0.25-256$ \\
\hline & Gentamicin & 4 & $>256$ & $0.25-256$ \\
\hline & Ciprofloxacin & 0.25 & 8 & $0.25-256$ \\
\hline \multirow[t]{3}{*}{ Klebsiella spp (5) } & Chloramphenicol & 8 & 16 & $0.25-256$ \\
\hline & Gentamicin & 64 & $>256$ & $0.25-256$ \\
\hline & Ciprofloxacin & 2 & 8 & $0.25-256$ \\
\hline \multirow[t]{3}{*}{ P. aeruginosa (1) } & Chloramphenicol & - & 64 & $0.25-256$ \\
\hline & Gentamicin & - & 64 & $0.25-256$ \\
\hline & Ciprofloxacin & - & 4 & $0.25-256$ \\
\hline
\end{tabular}

The coagulase negative staphylococci generate fewer controversies on its pathogenicity these days. They have been incriminated in chronic blepharits (2), Keratitis (24), and endophthalmitis (22). In Nigeria, the pathogenicity of the CNS has been established and is incriminated in various disease conditions; Ogbolu et al. thus advocate processing when isolated from repeated cultures (25). Their incrimination and inclusion in this study is thus not surprising, and their resistance patterns justify the discourse, which further show that resistance mechanisms are equally been evoked by these organisms, thus increasing their endemic status and enhancing their pathogenicity, especially when they reach deeper structures.

Most ocular isolates showed resistance using disc diffusion techniques to gentamicin $(54.6 \%)$ but more marked levels of resistance was demonstrated $\left(\mathrm{MIC}_{50}=32, \mathrm{MIC}_{90}>256\right.$ $\mu \mathrm{g} / \mathrm{ml}$ ) by broth dilution technique. Resistance to Gram negative rods and Staphylococcus aureus including MRSA strains was demonstrated. Third generation fluoroquinolone - levofloxacin was most efficacious using the disc diffusion test technique (93.4\%). The efficacy of this drug buttresses the reliability of the fluoroquinolones against conjunctival bacterial pathogens, especially the MRSA. Ciprofloxacin also had demonstrable clinical efficacy using both techniques. Susceptibility of MRSA strains was $83 \%$ using disc diffusion test, confirmed by broth dilution techniques $\left(\mathrm{MIC}_{50}<0.5\right)$. Resistance was however also demonstrated, with $\mathrm{MIC}_{90}=8.0 \mu \mathrm{g} / \mathrm{ml}$. These results are in sharp variance with Kotlus et al's observation in the United States, where 94\% resistance to ciprofloxacin was observed, with $\mathrm{MIC}_{50}$ $=8.0 \mu \mathrm{g} / \mathrm{ml}$, in the study, gentamicin was most efficacious (16). The efficacy of ciprofloxacin has also been demonstrated in Nigeria, this conforms to the study of Idu et al. where it was found to be most potent among other topical fluoroquinolones (20).

126 
Abuse of fluoroquinolones in the U.S may have led to the potent drug, whereas it's comparatively new status in Nigeria still ensures its potency.

On definitive prophylaxis pre-ocular surgery, this study may be quick to recommend the use of ciprofloxacin in topical formulations in Nigeria. However, discouragement of empirical therapy for the treatment of ocular infections is essential considering the increasing levels of resistance to commonly used antibiotics as has been shown in this study. The study affirms the high levels of the superbug MRSA among these species in eye infections in Nigeria, having varying resistance patterns. It also quantitatively validates reports of significantly reduced potency to commonly used topical antimicrobials - gentamicin and chloramphenicol. It

\section{REFERENCES}

1. Hentges DJ (1993): The anaerobic microflora of $t$ he human body, Clinical Infectious Diseases. 16(Supp14): S175.

2. McGulley JP, Dougharty JM, Deneam D (1982): Classification of chronic blepharitis. Ophthalmology 89:1173-1175.

3. Mozayemi RM, Lam S (1996): Phyctenular keraconjunctivitis and marginal Staphylococcal Keratitis. Indian Journal of Ophthalmology.13921395.

4. Fukuda M, Ohashi H, Matsumoto C, Mishima S, Shimomura Y (2002): Methicillin-resistant Staphylococcus aureus and methicillin resistant coagulase-negative Staphylococcus ocular surface infection efficacy of chloramphenicol eye drops. Cornea. 21 (Suppl): S86-S89.

5. Asonye CC, Ezelum C (2003): Bacterial aetiology of eye infections in Onitsha, Anambra, Nigeria. National Journal of Science. (2): 42-50

6. Houang E (2001): Microbial Keratitis in Hong Kong: Relationship to climate, environment and contact lens disinfection. Transactions of the Royal Society of Tropical Medicine and Hygiene. 95: 361-367.

7. Nagayama A, Nakao T, Taen H. In vitro activities of ofloxacin and four other new quinolinecarboxylic acids against Chlamydia trachomatis. Antimicrob Agents Chemother 1988; 32: 1735-7.

8. Bharathi MJ, Ramakrishnan R, Vasu S, Meenakshi R, Palaniappan R. In-vitro efficacy of antibacterials against bacterial isolates from corneal ulcers. Indian J Ophthalmol. 50: 109-14

9. Jarudi N, Golden B, Hoyme J, Tyson MD, Harter JG. Comparison of antibiotic therapy in presumptive bacterial conjunctivitis. $A m J$ Ophthalmol 1975; 79: 790-4.

10. Cagle GD, Abshire RL. Quantitative ocular bacteriology: a method for the enumeration and identification of bacteria from the skin-lash margin and conjunctiva. Invest Ophthalmol Vis Sci 1981; 20: 751-7.

11. Gelender H, Rettich C. Gentamicin-resistant Pseudomonas aeruginosa corneal ulcers. Cornea 1984; 3: 21-6. high rate of resistance to this 1 however shows the fluoroquinolones as unparalleled in the treatment of ocular infections. We therefore advocate for discontinuation of empirical therapy by physicians, and advise isolation of the causative bacterial agents, and subsequent susceptibility testing which should include the fluoroquinolones. The inability to isolate typically fastidious ocular pathogens like Streptococcus pneumoniae, Haemophilus influenzae, and Haemophilus aegypticus, should impel a clamour for the use of transport swabs in routine diagnosis of eye infections. Periodic re-evaluation of antimicrobial agents is essential in order to guide therapy, as well as to track and monitor resistance by organisms in this sensitive organ of vision.

12. Mehta NJ, Webb RM, Krohel GB, Smith RS. Clinical inefficacy of tobramycin and gentamicin sulfate in the treatment of ocular infections. Cornea 1984; 3: 228.

13. Arlene G (1992): Topical ofloxacin compared with gentamicin in the treatment of external ocular infections. British Journal of Ophthalmology. 76(12): 714-718.

14. Morrissey I, Burnett R, Viljoen L, Robbins M (2002): Surveillance of the susceptibility of ocular bacterial pathogens to the fluoroquinolones, vancomycin and gatifloxacin in Europe during 2001-2002. Journal of Infections 49: 109-114.

15. Goldstein MH, Kowalski RP, Gordon YJ (1999): Emerging fluoroquinolone resistance in bacterial keratitis. Ophthalmology. 206: 1313-1318.

16. Kotlus B, Wymbs R, Vellozi E, Udell I (2003): In vitro activity of Fluoroquinolones, Vancomycin, and Gentamicin against Methicillin Resistant Staphylococcus aureus Ocular isolates. American Journal of Ophthalmology. 95(4): 361-367E.

17. Barrow GI, Feltham RKA. Characters of Gramnegative bacteria. In: Cowan and Steel Manual for Identification of Medical Bacteria. $3^{\text {rd }}$ edition, Cambridge University Press, 1993; 94-149.

18. Clinical and Laboratory Standard Institute, CLSI (2007): Performance standards for antimicrobial susceptibility testing; seventh informational supplement M100-S17 Vol. 27 No. 1.

19. Goldstein FW, Acar JF (1995): Epidemiology of quinolones resistance: Europe and North and South America. Drugs (suppl 2): 36-42.

20. Idu FK, Odjimogho SE (2003): Susceptibility of conjunctival bacterial pathogens to fluoroquinolones: A comparative study of ciprofloxacin, norfloxacin and ofloxacin. Online Journal of Health Allied Sciences; 2: 1

21. Baum JL (1997): Bacterial conjunctivitis: Diagnosis and Treatment. APUA Newsletter. 15(4): 1, 4-5, 8 .

22. Tsuyoshi K, Seiji H (1998): Methicillin Resistant Staphylococcus aureus and Methicillin Resistant 
Coagulase Negative Staphylococcus from conjunctiva from pre-operative patients. Japan Journal of Ophthalmology. 42: 461-465.

23. Scott IU, Flynn HW Jr, Feuer W (1995): Endophthalmitis after secondary intraocular lens implantation. A case-control study. Ophthalmology . 102:1925-31.

24. Khosavri AD, Mehdinejad M, Heidari M (2007): Bacteriologic findings in patients with ocular infections and antibiotic susceptibility pattern of isolated pathogens. Singapore Medical Journal 48(8): 741-745.
25. Ogbolu DO, Daini OA, Alli OAT, Adesina OA, Odekanmi AA, Okanlawon BM, Olusoga-Ogbolu FF, Oni AA (2009): Coagulase Negative Staphylococci distribution in clinical samples in a tertiary hospital in Ibadan, Nigeria. Nigerian Journal on Health and Biomedical Sciences. 8(1): $36-40$ 